NBER WORKTNG PAPERS SERTES

THE GLOBAIIZATION OF INFOAMATION AND

CAPIIAL MOBIIITY

William H. Branson

Dwight M. Jaffee

Working Paper No. 3496

NATIONAL BUREAU OF EOONOMIC RESEARCH

1050 Massachusetts Averue

Cambridge, MA 02138

Octaber 1990

This paper was prepared for a Conference on Accounting and Financial Globalization at the Stern School of Business, New York University. The authors thank Michael Adler and seminar participants at Baruch College, the coments. School of Econanics, and the Paris Seminar on Macroeconomics for camments. This paper is part of NBER's research program in International Studies. Amy opinions expressed are those of the authors and not those of the National Bureau of Econanic Research. 
NBER Working Paper \#3496

October 1990

\section{THE GLOBALIZATION OF INFORMATION AND}

CAPITAL MOBILITY

\section{ABSTRACT \\ This paper provides a framework for analyzing the effects of} symmetric and assymetric changes in information about risk on equilibrium real interest rate spreads across countries. Following the literature on parameter uncertainty, improvements in information are modelled as reductions in estimated variances. The equilibrium interest differential is determined in a twocountry setting. The effects of changes in information on the differential are shown in cases where (a) all investors have the same information, (b) home investors have superior information about home assets, and (c) all investors experience an improvement in information about one asset. An improvemnet in information on European assets in "Europe 1992" will raise the interest differential on U.S. assets relative to European as investors shift toward European assets.

William H. Branson Woodrow Wilson School Princeton University princeton, NJ 08544
Dwight M. Jaffee Economics Department Princeton University Princeton, NJ 08544 
The trend toward globalization of information in financial markets has appeared to accelerate in recent years. Perhaps most importantly, the plans for "Europe 1992" provide for better flows of information in both goods and securities markets for the major European economies. The planned changes, for example, should lead to more uniform reporting and accounting systems. The effects of such improvements in the flow of information in financial markets are generally considered to be beneficial, since they create more integrated capital markets and more mobile capital flows. Given the amount of attention that is being paid to "Europe 1992", it would seem timely to develop a more detailed evaluation of the likely effects of improved information.

It is disappointing, therefore, to find that portfolio selection theory has not focused on analyzing the effects of an improvement in the quality of information, such as might arise from the forthcoming European changes.

Indeed, Robert Merton's presidential address for the American Finance Association (Merton [1987]) was directed at precisely this issue. Of course, there is an extensive literature which studies the role of such factors as transactions costs, taxes, and capital controls on international capital mobility. 1 However, as we discuss later, the effects of imperfect capital markets may differ substantially from the effects of imperfect information.

The main objective for this paper is to provide a framework for analyzing the effects of the globalization of information. We will focus, in particular, on how the globalization of information influences real interest rate spreads-differences in the levels of real interest rates among countries. We start, in Section 1, by introducing the factors that lead to real interest rate spreads.

1 For recent studies, see Adler and Dumas [1983], Obstfeld [1986], and Franke] [1989]. 
Section 2 then looks at the sources of imperfect information and at how the quality of information may vary among investors. Section 3 provides a formal portfolio selection model that links real interest rate spreads with imperfect information. Section 4 develops the main conclusions concerning the effects of the globalization of information.

\section{RBAL INTEREST RATE SPREADS}

Frankel and MacArthur [1988] provide a useful framework for analyzing the factors that cause real interest rates to vary across countries. The real interest rate spread is defined as:

$$
\text { [1] } \begin{aligned}
I-r^{*} & =\left(1-\pi_{p}\right)-\left(i^{*}-\pi_{p}^{*}\right) \\
& =\left(1-i^{*}\right)-\left(\pi_{p}-\pi_{p}{ }^{*}\right) .
\end{aligned}
$$

where $I$ is the real interest rate, 1 is the nominal interest rate, $\pi_{p}$ is the expected inflation rate, and asterisks represent foreign variables. By adding and subtracting the expected depreciation of the home currency $\pi e$, and then doing the same with the forward discount $\delta$, equation [1] becomes:

[2] $I-r^{*}=\left(1-i^{*}-\pi_{e}\right)+\left(\pi_{e}-\pi_{p}+\pi_{p}^{*}\right)$

and

[3] $r-r^{*}=\left(1-i^{*}-\delta\right)+\left(\delta-\pi_{e}\right)+\left(\pi_{e}-\pi_{p}+\pi_{p}^{*}\right)$.

Equation [2] shows that the real interest rate spread can be expressed as two terms, first the uncovered interest rate spread $\left(1-1^{\star}-\pi_{e}\right)$ and second the expected real exchange rate depreciation $\left(\pi_{e}-\pi_{p}+\pi_{p} *\right)$. This means that 
real interest rate spreads can result from factors in either financial markets-

-the failure of uncovered interest rate parity (UIP)--or real markets--the

failure of purchasing power parity (PPP).

Since the expected change in the exchange rate, $\pi_{e}$, is not observable, it is difficult to evaluate empirically whether deviations from UIP or PPP are the more important source of real interest rate spreads. Based on their empirical evidence, Frankel and MacArthur [1988] conclude that expected real exchange rate depreciation is the more influential of these two sources of real interest rate spreads. The evidence of Adler and Lehmann [1983], however, implies that PPP may still hold on an ex ante, if not ex post, basis. In this case, deviations from UIP would have to be the primary source of real interest rate spreads.

In interpreting equation [2], it is also important to recognize that the UIP and PPP terms may not be independent. That is, deviations from UIP may create deviations from PPP, and vice versa. In particular, the model in Section 3 below illustrates a case in which larger PPP deviations are the source of larger UIP deviations.

Equation [3] shows that the uncovered interest rate spread can be further decomposed into two terms, the first containing the covered interest rate spread ( $\left.i-i^{*}-\delta\right)$ and the second containing the forward exchange market risk premium $\left(\delta-\pi_{e}\right)$. This means that uncovered interest rate parity can fail to hold either because covered interest rate parity fails to hold or because there is a forward exchange market risk premium. The standard view in the recent 1iterature, consistent with the evidence of Frankel and MacArthur [1988], is 
that the covered interest rate differential is likely to be small empirically. 2

This implies that an exchange market risk premium is the most likely financial market source of real interest rate spreads.

Given that covered interest rate parity does hold, it is logically equivalent to represent the exchange market risk premium either as a deviation from uncovered interest parity (as in equation [2]) or as the difference between the expected exchange rate depreciation and the forward discount (as in equation (3]). Whichever interpretation is preferred, the international portfolio choice literature indicates that a variety of specific conditions in the two countries, such as unequal supplies of wealth and securities, or unequal commodity (consumption) preferences, can be the source of the risk premiums (see Adler and Dumas [1983]). The model developed in Section 3 1llustrates how this works.

Information plays a number of important roles in determining exchange market risk premiums. First, uncertainty is a necessary cordition for risk premiums to exist at all. Otherwise, if investment outcomes were known with certainty, then riskfree arbitrage would eliminate all risk premiums. Second, the particular form taken by stochastic processes can affect the measure used for uncovered interest rate parity. For example, for the model developed in Section 3 with continuous-time stochastic processes, the parity relationship between interest rates includes covariance terms that are omitted from equation [2]. Third, if the amount of uncertainty increases, then the size of risk premiums will generally rise. This result is illustrated in section 3 below. Fourth, asymetrical access to information--meaning that investors face

2 Frankel and MacArthur [1988] refer to potential deviations from covered interest rate parity as country risk, since such deviations would arise from capital controls and other country-specific restrictions on capital flows. 
different levels of uncertainty--can affect both the size and the specific form of risk premiums.

Even though information affects exchange market risk premiums in these various ways, the effects of changing the amount of information have not been closely studied. In this paper, we start to redress this shortcoming of the literature, by analyzing the role of imperfect information as a source of risk premiums and real interest rate spreads.

\section{Real Rate Spreads for Risky Securities}

Real interest rate spread equations, such as equations [1], [2], and [3], have been analyzed traditionally only for securities that have no default risk. To consider imperfect information, however, it is essential to include securities with default risk. Otherwise, if the securities are assumed to be free of default risk, then investors have no need to obtain information and there is thus no role for imperfect information. The solution is to expand equation [3] to cover risky securities--which can be interpreted as either equity securities or as risky debt securities.

For this purpose, let us suppose that $r$ and $r$ are the expected real returns and $i$ and $i^{*}$ are the expected nominal returns on two risky bonds. The expected returns (both nominal and real) on the two securities may include risk premiums that compensate investors for bearing the risk. Such risk premiums will tend to be greater the more risk averse are investors and the greater the extent to which the risk of default is not diversifiable--as, for example, when default depends on the macroeconomic performance of the economy.

If we denote the risk premiums on the home and foreign securities as $\tau$ and 
$\tau *$ respectively, then equation [2] can be modified by adding and subtracting $\tau$ and $\tau *$ :

[4] $r-r^{*}=\left[(i-\tau)-\left(i^{*}-\tau^{*}\right)-\pi_{e}\right]+\left(\tau-\tau^{*}\right)+\left(\pi_{e}-\pi_{p}+\pi_{p}^{*}\right)$

The terms $(i-\tau)$ and $\left(i *-\tau^{*}\right)$ are the expected returns net of risk premiums for the home and foreign securities respectively, while the term $\left(\tau-\tau^{*}\right)$ is the difference between the two risk premiums. Of course, if the two securities have equal levels of risk and investors evaluate the risk without regard to the country or currency in which the securities are issued, then $\tau$ might equal $\tau^{*}$, But even with equal risk, unequal risk premiums may still arise whenever the demand/supply balance for risk is different in the two countries. In Section 3, we will analyze how the relationship between real interest rate spreads and security risk is affected by improved flows of information.

\section{THE "GLOBALIZATION" OF INFORHATION}

We next consider how differences in information affect international portfolio decisions and the level of risk premiums. The available information concerning a country's securities may vary depending on such factors as the size or stage of development of the country or the location of the investors. As one case, information may be of lower quality in smaller or in less developed countries, reflecting the absence of economies of scale for creating uniform accounting standards or for carrying out investments that provide additional information.

As another case, the quality of security information in each country may be higher for local investors than for foreign investors. That is, local investors will generally have an advantage in locating and interpreting 
information about local securities. In this context, "Europe 1992" provides an example where the quality of information for the securities of a region is about to improve. As these countries adopt more uniform accounting and reporting standards, the informational advantages of local European investors relative to foreign investors might disappear.

To evaluate the effects of an improvement in information, we have to quantify what we mean by the quality of information. We will do that here within the context of mean/variance portfolio selection models. In these models, investors require parameter values for the expected return vector and the variance/covariance matrix of returns. Standard treatments of portfolio selection theory assume efther that investors know these parameters with certainty or that estimates of the parameters can be used as if they were certain, given that the true values are unknown. In either case, this leaves no room for situations in which there exists a range of quality levels for information. An alternative framework is thus necessary in order to analyze the effects of changing the quality of information.

\section{Parameter Uncertainty and Estimation Risk}

A more general, and for us more useful, approach for dealing with information can be derived from the finance literature concerned with parameter uncertainty. 3 The starting point is to recognize that because investors generally do not know the true parameters, they have to use statistical techniques to construct estimates. Moreover, although the estimation process provides a set of point estimates for the parameters, a band of uncertainty

3 See, for example, Barry and Brown [1985], Bawa, Brown, and Klein [1979], or Brown [1979]. 
necessarily remains. The parameter uncertainty literature analyzes how this estimation risk is properly incorporated in portfolio selection decisions and models.

To illustrate how this works, assume that the true information is given by the set $\theta=\{\mu, \Sigma\}$, with $\mu$ the expected return vector and $\Sigma$ the variance/covariance matrix. The investor maintains a diffuse (uninformative) prior concerning the parameters, but has access to $T$ data observations from which the parameters can be estimated. Let the resulting point estimates for the parameters be $\theta^{*}=\left\{\mu^{*}, \Sigma^{*}\right\}$. Although this example uses the number of observations $T$ to measure the quality of information, the parameter uncertainty literature recognizes that other improvements in information quality can affect the variance/covariance matrix in a comparable manner. 4

While standard portfolio selection theory treats the point estimates $\theta^{*}$ as if they were the true parameters, the parameter uncertainty literature uses the predictive distribution to take parameter uncertainty into account (see Bawa, Brown, and $\mathrm{klein}$ [1979]). The upshot is that different parameter values, namely $\dot{\theta}=\left\{\mu^{*},(1+[1 / T]) \Sigma^{*}\right\}$, are used for making portfolio decisions. In particular, the estimated variance/covariance matrix $\Sigma^{*}$ is multiplied by an adjustment factor, $1+(1 / T)$, which is generally greater than one.

The adjustment factor approaches one only as the number of observations $T$ approaches infinity--that is, as the information becomes certain. Otherwise, the effect of parameter uncertainty is to raise the size of the perceived variance/covariance matrix. We will use this approach to model an improvement in information as if it created a reduction in the parameters of the

4 See, in particular, Barry and Brown [1985], p. 413. 
varlance/covariance matrix used by investors for determining their optimal portfolios.

An alternative approach is 11 lustrated in the paper by Michael Adler and Bhaskar Prasad, "Optimal Forelgn Currency Hedging When Information is Imperfect," which also appears in this symposium. In their approach, new Information becomes steadily available to the investor, who uses it to update the prior density. In our approach, in contrast, the change in the quality of information is a one-time event.

Capital Market Imperfections and Informational Imperfections

The parameter uncertainty model for imperfect information can be compared with the barriers to international investment model for imperfect capital markets. 5 In the barriers model, capital masket imperfections--such as transactions costs and comparable impediments to trade--are treated as implicit taxes on the returns to foreign investment. Reducing these barriers to international investment thus raises the level of the expected return for investors. In contrast, with the parameter uncertainty model, improving information quality decreases the size of the perceived variance/covariance parameters.

The main point here is that an improvement in information quality, such as the plans for "Europe 1992," can affect investor decisions through the variance/covariance matrix, without directly affecting the expected returns. Since an increase in expected returns may seem more tangible than a reduction in parameter uncertainty, an informational change may appear less important, even when it creates exactly the same increase in investor welfare.

5 See Black [1974], Stulz [1981], and the survey in Adler and Dumas [1983]. 


\section{Endogenous Information Quality}

Our discussion has so far treated information quality as an exogenous factor in the model, which is sensible when looking at the effects of developments such as "Europe 1992." There are other contexts, however, in which the quality of information should be treated as an endogenous variable.

One important case occurs when access to information requires an expenditure of resources by the investor. 6 The cost of information can be efther a fixed cost or a variable cost that rises with the amount of information. The cost of information may also differ between local and foreign investors, with local investors facing lower costs than foreign investors for obtaining local security information.

Even when local investors have lower information costs, their expected returns after subtracting information costs may also be lower, since the lower cost of information will cause them to purchase more information. Of course, local investors will also be receiving the benefits of higher quality information. The upshot is that information may affect both the expected return vector and the variance/covarfance matrix in equilibrium, thus combining what we earlier called the bartiers and the parameter uncertainty models. Another case of endogenous information arises when investors can infer information by observing the market price, In this case, the market will include both informed investors who can directly obtain information at a low cost and uninformed investors for whom the cost of information is high, even prohibitive. Although the uninformed investors are at a disadvantage, Grossman and Stiglitz [1980] have shown that the market price may provide uninformed

6 See Ho and Michaely [1988] for a recent model of this type. 
investors with free access to the information held by the informed investors. To the extent that this happens, it reduces the incentive for informed investors to allocate resources to obtain information. Thus, even when information is endogenous, it is still likely to be imperfect.

Another aspect of markets with informed and uninformed investors is that the welfare effects of improved information become more complex. For example, the model of Stein [1987] develops a case in which the entry of additional uninformed traders creates random variations in market prices, which decrease the welfare of the informed traders. In the context of "Europe 1992," a comparable result would be that improving the quality of information available to non-European investors could reduce the welfare of European investors who lose some of their advantage in terms of information.

Still another effect of endogenous information--adverse selection--may arise when particular classes of investors can be explicitly recognized. A good example in the case of international investment is that local borrowers (and other sellers of securities) may realize that less information is available to foreign investors than to local investors. As a result, local borrowers may offer to foreign investors securities that have an inferior expected return/risk ratio compared to the securities offered to local investors. Foreign investors will then tend to withdraw from such markets, in the same way that they do when facing investment barriers or lower information quality.

The Importance of adverse selection will vary across markets, depending on the extent to which the identity of local and foreign (or informed and uninformed) investors is relevant. For example, adverse selection should not be a serious problem on organized stock markets, where the identity of the 
traders does not directly enter into the transaction. 7 On the other hand, in banking markets, the quality of loans made depends critically on the information available to the lender. In this case, foreign banks may find that their borrower applicant pool is of lower quality than the pool available to local banks.

\section{Conclusions Regarding Information}

The portfolio selection model that we develop in the next section provides a convenfent, but simplified, starting point for evaluating the effects of higher quality information. The model is based on the parameter uncertainty approach, in that higher quality information is assumed to reduce the size of the variance/covariance parameters, which are treated as exogenous. We also consider various cases in which domestic and foreign investors have differential access to information. Since the supply of information is exogenous, however, there is no explicit role for adverse selection.

\section{A HODEL OF THS EQUILIBRIUY RISK PREMIUM}

This section of the paper develops a formal model of the equilibrium risk premium on nowinal risky assets, and shows how it is affected by improvements in information, interpreted as reductions, in several ways, of the estimated variance of returins. The model has two risky assets, one domestic and one foreign, and two representative investors, domestic and foreign, who hold portfolios composed of both assets. The returns on both assets follow stochastic processes in continuous time, as do the exchange rate and the two

If necessary, foreign traders could even use local agents to complete their transactions. Of course, corrupt local agents can still take advantage of traders, as we have seen recently in some U.S. futures markets.

$$
--12--
$$


price levels used to deflate wealth by the two investors. ${ }^{8}$ This represents an extension of the models developed in Branson and Henderson [1985) and Fraga $[1986]$.

We first derive the individual investors' portfolio demands, following the example in Branson and Henderson [1985]. We then solve for the market equilibrium risk premium, following the example in Fraga [1986]. The terms in this risk premium can be interpreted as stochastic deviations from uncovered interest parity (UIP) and purchasing-power parity (PPP). This analysis unifies the literature on international risk premia, exemplified by Frankel and MacArthur [1988], and the finance literature on portfolio demends.

In the following analysis, we study the effects on asset demands and the risk premium of changes in information characterized by estimates of the variance of the stochastic returns. We first look at a change in information about the "foreign" asset that is shared by all market participarts. Then we study the asymmetric case in which the home investors' estimate of the variance on the foreign asset differs from the foreign investors' estimate. This could be interpreted as the effect of an action that reduces the foreign investors' information advantage. We find that in both cases, an improvement in information on the foreign asset shifts demand in that direction, reducing the size of the foreign asset's risk premium.

\section{International Asset Demands: Home Investor}

We begin with the problem facing the domestic investor, whose real wealth is given by

${ }^{8}$ Compared to Branson and Henderson [1985] and Fraga [1986], this sets $\alpha^{*}=0$, and makes the returns stochastic, to give us the case of risky assets. 
[5] $\tilde{W}=\frac{W}{P}=\frac{B+E F}{P}$,

where $B$ and $F$ are the holdings of domestic and foreign risky assets, $E$ is the nominal exchange rate in units of home currency per unit of foreign exchange, and $P$ is the home price level. There is no riskless asset in the model.

The problem is to choose portfolio shares given by

[6] $B=\lambda W$, and $[7] \quad E F=(1-\lambda) W$,

to waximize an objective function given by

[8] $V=\varepsilon\left(\frac{d \bar{W}}{\tilde{W}}\right)-\frac{1}{2} R \operatorname{var}\left(\frac{d \tilde{W}}{\tilde{W}}\right)$,

where $\varepsilon$ denotes expected return and var is variance. As discussed in Branson and Henderson [1985], this time-separable form of the objective function, and its mean-variance form, are consistent with a HARA utility function of the form $U=\frac{1}{8} C^{\gamma}$, where the coefficient of relative risk aversion in the objective function is $R=\gamma-1$. The stochastic processes for the rates of return are specified as:

[9] $\frac{d B}{B}=i_{b} d t+\sigma_{b} d z_{b}$, and

$[10] \frac{d F}{F}=i_{f} d t+\sigma_{f} d z_{f}$,

The exchange rate and two price levels follow stochastic processes given by

$[11] \frac{d E}{E}=\pi_{e} d t+\sigma_{e} d z e^{\prime}$ 
[12] $\frac{d P}{P}=\pi_{p} d t+\sigma_{p} d z$, and

[13] $\frac{d P^{\star}}{P^{\star}}=\pi_{P}^{\star} d t+\sigma_{p}^{\star} d z_{p}^{\star}$

Here the returns, the exchenge rate, and the price levels all follow geometric Brownian motion with expected drift given by the terms in dt and variances $\sigma_{i}^{2}$. Only $P$ is relevant for the home investor.

To solve the home investors' problem, first take the Ito differential of [5] for $d \tilde{W}$, divide through by expressions [6] and [7] for $W / P$, and then substitute [6] to [13] into the result. ${ }^{9}$ This yields for d $\tilde{w} / \tilde{W}$,

$$
\begin{aligned}
{[14] \frac{\mathrm{d} \tilde{W}}{\tilde{W}}=} & {\left[\lambda i_{b}+(1-\lambda) i_{f}+(1-\lambda) \pi_{e}-\pi_{p}+(1-\lambda) \rho_{e f}\right.} \\
& \left.-\lambda \rho_{b p}-(1-\lambda) \rho_{f p}-(1-\lambda) \rho_{e p}+\sigma_{p}^{2}\right] d t \\
& +\lambda \sigma_{b} d z_{b}+(1-\lambda) \sigma_{f} d z_{f}+(1-\lambda) \sigma_{e} d z_{e}-\sigma_{p} d z_{p},
\end{aligned}
$$

where the term in $d t$ is the expected return in the objective function in equation [8] and the square of the terms in $d z_{i}$ is the variance:

${ }^{9}$ See Branson and Henderson [1985] for an example of the arithmetic involved. 
[15] $\operatorname{var}\left[\frac{d \bar{W}}{\bar{W}}\right]=\lambda^{2} \sigma_{b}^{2}+(1-\lambda)^{2} \sigma_{f}^{2}+(1-\lambda)^{2} \sigma_{e}^{2}-\sigma_{p}^{2}$

$$
\begin{array}{r}
+2\left[\lambda(1-\lambda)\left(p_{\mathrm{bf}}+\rho_{\mathrm{be}}\right)+(1-\lambda)^{2} \rho_{\mathrm{fe}}\right. \\
\left.\quad-\lambda \rho_{\mathrm{pb}}-(1-\lambda) \rho_{\mathrm{pf}}-(1-\lambda) \rho_{\mathrm{pe}}\right] .
\end{array}
$$

In equations [14] and [15] the $p$ terms are the covariances, $p_{1 j}=\sigma_{1} \sigma_{j} r_{1 j}$, where $r$ is the correlation coefficient.

Substituting the dt term in [14] into the objective function in [8] for $\varepsilon(d \bar{W} / \bar{W})$ and the expression in [15] for $\operatorname{var}(d \bar{W} / \bar{W})$, differentiating with respect to $\lambda$, and solving the first order conditions, yields the portfolio demand

$[16] \lambda=\frac{D+C+R Z}{R A}=\frac{Z}{A}+\frac{D+C}{R A}=\frac{R-1}{R} \frac{Z}{A}+\frac{1}{R} \frac{D+C+Z}{A}$,

where the terms are:

$D=$ uncovered interest differential $=i_{b}-i_{f}-\pi_{e} ;$

$C=$ covariance terms that enter expected return $=-\rho_{\text {ef }}-\left(p_{b p}-p_{f p}-p_{\text {ep }}\right)$;

$A=\sigma_{e}^{2}+\sigma_{f}^{2}+\sigma_{b}^{2}+2\left(p_{e f}-p_{b f}-p_{b e}\right)=\operatorname{var}(B-E F)>0 ;$

$z=\sigma_{e}^{2}+\sigma_{f}^{2}+2 p_{e f}-\left(p_{b f}+p_{b e}\right)+\left(p_{b p}-\rho_{f p}-\rho_{e p}\right)$.

The demand for the home asset in [16] is written in two separable forms to highlight the role of the minimum-variance portfolio given by $\lambda_{\min }=\mathrm{Z} / \mathrm{A} .10$ The entire home investors' portfolio in the first separable form can be written as

10 This is the solution for $\lambda$ obtained by minimizing the portfolio variance in equation (15). See also Branson and Henderson (1985). 
[17]

$$
\lambda=\lambda_{\min }+\frac{D+C}{R A}
$$

$$
1-\lambda=\left(1-\lambda_{\min }\right)-\frac{D+C}{R A} \text {. }
$$

Here all of wealth is held in the minimum-variance portfolio, 1.e., $\lambda_{\min }+\left(1-\lambda_{\min }\right)=1$, combined with holdings of a zero net worth speculative portfolio that are inversely proportional to RA. The second separable form of the portfolio in [16] shows it as a weighted average of the minimum-variance portfolio and the portfolio of a "logarithmic" investor with $R=1$, 1.e. $(D+C+Z) / A$. This is the form favored by Adler and Dumas [1983].

We can immediately check the derivative of $\lambda$ with respect to $\sigma_{f}^{2}$, which enters $A$ and $Z$ linearly, and $D$ and $C$ not at all. The result is given by

[18] $\frac{\partial \lambda}{\partial \sigma_{f}^{2}}=\frac{1}{A}(1-\lambda)$,

which is positive if $\lambda<1$; that is, less than all of wealth is held in the home asset. In this case an increase in the home investors' estimate of $\sigma_{f}^{2}$, holding all covariances constant, increases the share of the home asset in the portfolio, 1.e., drives the home investor home. If $\lambda>1$, so $(1-\lambda)<0$, the home investor is borrowing abroad to hold more than all his wealth in home assets. In this case, $\partial \lambda / \partial \sigma_{f}^{2}$ is negative. An increase in $\sigma_{f}^{2}$ reduces the extent to which the investor borrows abroad.

It will be useful in interpreting later results to study at this point the derivative of $\lambda$ with respect to $\sigma_{f}$, holding all correlation coefficient $r$ 's constant. Using the definition of the covariance in terms of the correlation coefficient $\rho_{f i}=\sigma_{1} \sigma_{f} r_{f i}$, we obtain the derivatives of $A, C$, and $Z$ with respect to $\sigma_{f}$ shown below in equations [33]. Using those, we obtain the result $--17--$ 
[19] $\frac{\partial \lambda}{\partial \sigma_{f}}=\frac{1}{A}\left\{2(1-\lambda) \sigma_{f}+(2 \lambda-1) \sigma_{b} r_{b f}\right.$

$$
\left.+\left[2(1-\lambda)-\frac{1}{R}\right] \sigma_{e} r_{e f}-\left(1-\frac{1}{R}\right) \sigma_{p} r_{p f}\right\} .
$$

First we note that if all $r^{\prime} s=0$, the expression in [19] is equivalent to [18]: an increase in $\sigma_{f}$ directly increases $\lambda$. The sign of the coefficient of $\sigma_{b} r_{b f}$ is unclear. Below we assume that $r_{b f} \approx 0$. The sign of the coefficient of $\sigma_{p} r_{p f}$ is negative; below we assume $r_{p f} \approx 0$. The sign of the coefficient of $\sigma_{e} r_{e f}$ is also unclear. Below we assume $r_{e f}>0$, so this coefficient should be positive to contribute to an increase in $\lambda$. It is sufficient for this coefficient to be positive that $\lambda<0.5$ assuming $R \geq 1$.

\section{Demand by the Foreign Investor}

The foreign investors' real wealth is given by

[20] $\tilde{W}^{*}=\frac{W^{*}}{P^{*}}=\frac{\left(B^{*} / E\right)+F^{*}}{P^{*}}$

The foreign objective function is the same as [8] with $\tilde{w}^{*}$ substituted for $\tilde{w}$.

The foreign investors' portfolio shares are given by

[21] $\mathrm{B}^{*} / \mathrm{E}=\lambda^{*} W^{*}$, and $[22] \mathrm{F}^{*}=\left(1-\lambda^{*}\right) W^{*}$.

We assume at this stage that information sets of the two investors are identical, so the foreign investor observes the same stochastic processes [9][13] as the home investor. We also assume equal degrees of risk aversion. Then, following the same procedure for solving the foreign investors' portfolio problem as for the home investor yields the foreign demand for the home asset: 
[23] $\lambda^{\star}=\frac{D+C^{\star}+R Z^{*}}{R A}=\frac{Z}{A}^{\star}+\frac{D+C^{*}}{R A}$.

Here the terms are as already defined for $D$ and $A$, plus

$C^{*}=\sigma_{e}^{2}-p_{e b}-\left(p_{b p^{*}}-p_{f p^{*}}-p_{e p^{*}}\right)$, and

$z^{\star}=\sigma_{f}^{2}-\left(p_{b f}-\rho_{e f}\right)+\left(p_{b p^{*}}-\rho_{f p^{*}}-p_{e p^{*}}\right)$.

Again, the foreign investors' portfollo can be characterized in terms of a minimum-variance portfolio $\lambda_{\mathrm{m}_{i n}}^{\star}=z^{\star} / A$ and $1-\lambda_{\mathrm{m} i n}^{\star}$, plus a speculative portfolio inversely proportional to RA.

Again, we can check the effect of an increase in $\sigma_{f}^{2}$ on the foreign investors portfolio. Noting that $\sigma_{f}^{2}$ enters linearly in $A$ and $Z^{*}$, and not at all in $D$ or $C^{\star}$, we have

[24] $\frac{\partial \lambda^{*}}{\partial \sigma_{f}^{2}}=\frac{1}{A}\left(1-\lambda^{*}\right)>0$ if $\lambda^{*}<1$,

similar to the result for the home investor. An increase in the commonlypercelved riskiness of the foreign asset, represented by an increase in $\sigma_{f}^{2}$ holding all $p^{\prime} s$ constant, drives both investors toward the home asset.

It will also be useful in interpreting later results to obtain here the derivatives of $\lambda{ }^{*}$ with respect to $\sigma_{f}$ and $\sigma_{b}$, holding all $I^{\prime}$ s constant. The first will be useful in examining the effect of an increase in identical market-wide information on returns on one asset (here F) on the equilibrium risk premium D. The second will be useful in looking at the effects of an improvement in each set of investor's information about the returns on the others' assets. 
Following the same procedure used earlier for $\partial \lambda / \partial \sigma_{f}$, we obtain

[25] $\frac{\partial \lambda^{*}}{\partial \sigma_{f}}=\frac{1}{A}\left\{2\left(1-\lambda^{*}\right) \sigma_{f}+\left(2 \lambda^{*}-1\right) \sigma_{b} r_{b f}\right.$

$$
\left.+\left(1-2 \lambda^{*}\right) \sigma_{e^{r}}{ }_{e f}-[(R-1) / R] \sigma_{p^{*}} r_{p^{*} f}\right\} .
$$

The first two terms are the same as in $\partial \lambda / \partial \sigma_{f}$, with $\lambda$ in for $\lambda$. The sign of the coefficient of the $\sigma_{e} r_{e f}$ term is again unclear, because of conflicting effects from $Z^{*}$ and $A$. The sign of the coefficient of the $\sigma_{p^{*}} r_{p^{*} f}$ is negative. An increase in the covariance of $P^{*}$ and the return on $F$ makes the foreign asset less risky to the foreign investor.

For the effect of $\sigma_{b}$ on $\lambda^{*}$, we obtain

[26] $\frac{\partial \lambda^{*}}{\partial \sigma_{b}}=\frac{1}{A}\left[-2 \lambda^{*} \sigma_{b}+\left(2 \lambda^{*}-1\right) \sigma_{f} I_{b f}\right.$

$$
\left.+\left(2 \lambda^{*}-\frac{1}{R}\right) \sigma_{e} r_{e b}+\left(1-\frac{1}{R}\right) \sigma_{p^{*}} r_{b p *}\right]
$$

In general, we would expect an increase in $\sigma_{b}$ to reduce forelgn demand for the home bond. The first term in [26] is negative. The sign of the coefficient of $\sigma_{f} r_{b f}$ is unclear, but later we assume $r_{b f}=0$. The coefficient of $\sigma_{e} r_{e b}$ is unclear. We assume $r_{e b}<0$, so $\lambda^{*}>0.5$ would ensure that the term is positive. The coefficient of $\sigma_{p^{*}} r_{b_{p}}$ is positive, but we assume $r_{b^{*}}=0$.

\section{Conditions for Home Asset Preference (HAP)}

Since the home and foreign investors deflate nominal wealth by different deflators, we wish to see the conditions under which HAP holds. We define HAP as $\lambda-\lambda *>0$. From [16] and [23], 
$\lambda-\lambda^{*}=\frac{1}{R A}\left[C-C^{*}+R\left(Z-Z^{*}\right)\right]$.

Checking the definitions of $C, C^{\star}, Z$, and $Z^{\star}$ will confirm that

$C-C^{*}=-\left(Z-Z^{*}\right)$, so we have for HAP

[27] $\lambda-\lambda^{*}=\frac{\mathrm{R}-1}{\mathrm{RA}}\left(\mathrm{Z}-\mathrm{Z}^{*}\right)$,

where:

[28]

$$
\begin{aligned}
\left(Z-Z^{*}\right)=\left(\sigma_{e}^{2}-p_{b e}+p_{e f}\right) & -\left(p_{e p}+p_{f p}-p_{b p}\right) \\
& +\left(p_{e p^{*}}+p_{f p^{*}}-p_{b p^{*}}\right) .
\end{aligned}
$$

If $R>1,\left(Z-Z^{*}\right)>0$ is sufficient for HAP. How do we interpret this condition?

First, if the assets were not risky, with non-stochastic returns we would have

$$
z-z^{\star}=\sigma_{e}^{2}+p_{e p *}-p_{e p},
$$

as in Fraga [1986]. If PPP were to hold ex post, this would be zero. 11 If PPP does not hold ex post, as the evidence overwhelmingly indicates [See Frenkel [1981] or Frankel and MacArthur [1988]], then a larger, more positive pep or a smaller, more negative, Pep* would reduce HAP. This is an intuitive result. From equation [5] for the home investors' real wealth, a larger Pep reduces the risk in holding the foreign asset $F$, reducing $\lambda$. From equation [20] for

${ }^{11}$ See Appendix, Section 1. 
the forelgn investors' real wealth, a more negative $\rho_{\text {ept would reduce the risk }}$ in holding the home asset $R$, increasing $\lambda^{\star}$.

Second, if the asset returns are risky, but the price indexes are nonstochastic, we have

$$
Z-Z^{*}=\sigma_{e}^{2}-\rho_{b e}+\rho_{e f} \cdot
$$

If UIP were to hold ex post, this would be zero. 12 This, too, is an intuitive result. From the point of view of the home investor, an increase in the stochastic deviations from UIP makes the return on the foreign asset $F$ more volatile, increasing $\lambda$. From the point of view of the foreign investor, an increase in these deviations makes the return on the home asset more volatile, reducing $\lambda^{*}$.

The remaining terms in $Z-Z^{*}$ are the covariances of the asset returns and price levels:

$$
\left(p_{b p}-p_{f p}\right)+\left(p_{f p^{*}}-p_{b p^{*}}\right) .
$$

From [6] for the home investors' wealth, it is clear that an increase in the covariance of the domestic price level and the home bond return relative to the covarfance of the domestic price level and the foreign asset will increase $\lambda$. For the foreign investor, an increase in the covariance of $F$ and $P$ * relative to that of $B$ and $P^{*}$ will reduce $\lambda^{*}$.

Thus the conditions for HAP are readily interpreted in terms of stochastic deviations from PPP and UIP, and the covariances of nominal asset returns and price levels.

${ }^{12}$ See Appendix, Section 2. 


\section{Market Equilibrium with Identical Information}

We can now proceed to the solution for the equilibrium risk premium, which we have defined above as $D=i_{b}-i_{f}-\pi_{e}$. Following the way Fraga [1986] set up the problem, we note that market equilibrium for the domestic asset $B$ requires that

[29] $b=w \lambda+(1-w) \lambda^{*}$, where $b=B /\left(W+E W^{\star}\right)$ and $w=W /\left(W+E W^{*}\right)$. Substitution from equations [16] for $\lambda$ and [23] for $\lambda^{*}$ and solving for $D$ yields the equilibrium risk premium with identical information and risk aversion:

[30] $D=R A b-w(R-1)\left(Z-Z^{*}\right)-\left(C^{*}+R Z^{*}\right)$.

Here, consistent with the macroeconomic literature, an increase in the relative supply of the domestic asset b will increase the risk premium, and a transfer of wealth to domestic investors will reduce it, assuming HAP holds, that is, $z-z^{*}>0$.

One immediate result can be obtained by inspection of the expression for $D$ in [30]. The variance and covariance terms all enter linearly in $A, Z, Z^{\star}$, and $C^{*}$. So a proportional increase in all variances, representing a general increase in riskiness, would expand $D$ around zero, making it larger in absolute value by the percentage increase in riskiness, measured by the variances and covariances.

We can now ask what effect a change in the commonly-perceived riskiness of the foreign asset has on the equilibrium risk premium $D$. We have two alternative ways of characterizing this perceived increase in riskiness. The 
first is an increase in $\sigma_{f}^{2}$, holding all covariance $\rho_{f i}$ terms constant. 13 This yields a clear cut result. The second is an increase in $\sigma_{f}$, holding all correlation coefficients $r_{f i}$ constant, so that all the $p_{f i}$ change by $\sigma_{i} r_{f i} d \sigma_{f}$. These results require further interpretation.

First, we note that $\sigma_{f}^{2}$ enters only $A, Z$, and $Z^{*}$ in equation [30], with each having a partial derivative with respect to $\sigma_{f}^{2}$ of unity. So on the first interpretation of an increase in the riskiness of $F$, we have

[31] $\frac{\partial D}{\partial \sigma_{f}^{2}}=R(b-1)<0$.

An increase in the commonly-perceived riskiness of $F$ reduces the size of the risk premium on the home asset B. Conversely, if the perceived riskiness of European assets were reduced by the 1992 actions, the dollar asset risk premium would rise as investors shifted toward European assets.

Now we consider an increase in $\sigma_{f}$, holding all $r$ 's constant. From [30] we have the differential:

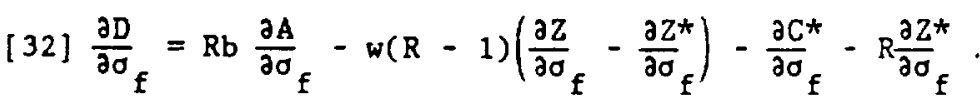

From the definitions of the terms A, Z, Z*, C, and $C^{*}$,

$$
\begin{aligned}
& \frac{\partial A}{\partial \sigma_{f}}=2\left(\sigma_{f}+\sigma_{e} r_{e f}-\sigma_{b} r_{b f}\right) ; \\
& \frac{\partial Z}{\partial \sigma_{f}}=2 \sigma_{f}-\sigma_{b} r_{b f}+2 \sigma_{e} r_{e f}-\sigma_{p} r_{p f} ;
\end{aligned}
$$

${ }^{13}$ This implicitly assumes that the absolute values of all correlation coefficients involving the return in the foreign assets are reduced.

$$
--24--
$$




$$
\begin{aligned}
& \text { [33] } \frac{\partial Z^{*}}{\partial \sigma_{f}}=2 \sigma_{f}-\sigma_{b} r_{b f}+\sigma_{e} r_{e f}-\sigma_{p^{*}} r_{p_{f} f} ; \\
& \frac{\partial C}{\partial \sigma_{f}}=-\sigma_{e} r_{e f}+\sigma_{p} r_{p f} \\
& \frac{\partial C^{\star}}{\partial \sigma_{f}}=\sigma_{p^{\star}}{ }^{r_{p^{*} f}} .
\end{aligned}
$$

Inserting the relations in [33] into [32] and gathering terms yields

$$
\begin{aligned}
{[34] \frac{\partial D}{\partial \sigma_{f}}=} & 2 R(b-1) \sigma_{f}-R(2 b-1) \sigma_{b} r_{b f} \\
& +[R(2 b-1)-w(R-1)] \sigma_{e} r_{e f} \\
& +w(R-1) \sigma_{p} r_{p f}+[(R-1)(1-w)] \sigma_{p^{*}} r_{p^{* f}} .
\end{aligned}
$$

Note that if all $r^{\prime} s$ (and therefore $p$ 's) are zero, [34] for $\partial D / \partial \sigma_{f}$ is equivalent to $[31]$ for $\partial D / \partial \sigma_{f}^{2}$, holding $a 11 \rho$ 's constant. The signs of the coefficients in [33] are as follows:

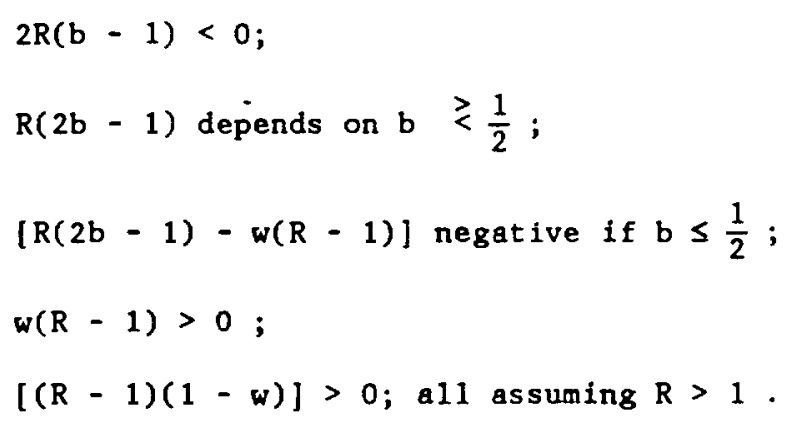


The negative sign for the term in $\sigma_{f}$ and the uncertain sign for the term in $\sigma_{e} r_{e f}$ are consistent with the results for $\partial \lambda / \partial \sigma_{f}$ in equation [19] and $\partial \lambda * / \partial \sigma_{f}$ in equation [25]. The overall result depends on the signs of the correlation coefficients. We make the following assumptions:

1. $r_{b p}, r_{f p^{*}}>0$; nominal returns are positively correlated with own inflation.

2. $r_{e p}>0 ; r_{e p^{\star}}<0$; devaluation raises the domestic price level and lowers the foreign.

3. $r_{e b}<0 ; r_{e f}>0 ; a$ shift in the return differential toward $F$ generates a depreciation.

4. $r_{b f}, r_{f p}, r_{b p^{*}}=0$.

With these presumptions, the second and fourth terms in [34] become approximately zero, the first is negative, the fifth is positive, and the third is unclear, but likely to be negative. The positive term in $r_{p * f}$ represents the reduction in risk on the real return on $F$ as the covariance of $P^{*}$ and the $F$ return rises.

The uncertainty regarding the term in $\sigma_{e} r_{e f}$ arises from the possibility that $R(2 b-1)$ is positive. The $2 b$ term appears because the overall variance term RA is in the denominator of both $\lambda$ and $\lambda^{*}$, so an increase in $\sigma_{f}$ reduces $\lambda$ and $\lambda^{*}$ by increasing $A$. This alone would require an increase in $D$ to maintain equilibrium. This is offset by the positive effects through $Z$ and $Z^{*}$ in the numerators of $\lambda$ and $\lambda^{*}$. Thus is it likely that the term in $\sigma_{e} r_{e f}$ is negative; it is sufficient that $b=0.5$.

Thus the general conclusion in the case of identical information is that a reduction in riskiness of one asset shifts asset demands toward that asset, increasing the risk premium in the other asset. The quantitative effects are 
given by equations [21] and [34] in our two cases, which are the same if all Pfi terms are zero.

\section{Market Equilibrium with Asymmetric Biased Information}

The experiments above assumed that information about the volatility of the returns on the foreign asset improved identically for all investors. In this section we ask what happens to the uncovered differential $D$ if information improves for only one set of investors. Specifically, we will assume that home and foreign investors mag have different estimates of the variance of the returns on $F$; the home investors' $\sigma_{f}^{2}$ differs from the foreign investors' $\sigma_{f}^{* 2}$.

This would be the case, for example, if the foreign investors had better information on their home assets than the home investors have. A reduction in $\sigma_{f}^{2}$ would represent an improvement in home investors' information about foreign assets. This could be a result, for example, of the integration of European financial markets in 1992. Non-European investors might acquire better (or cheaper) information about European assets with no compensating change in the knowledge available to Europeans on non-European assets.

The procedure we follow is first to write the market equilibrium condition for $D$, and then to calculate $\partial D / \partial \sigma_{f}^{2}$, holding $\sigma_{f}^{* 2}$ and all covariance constant. This is equivalent to the first experiment above, but assumes that only the home investors' information changes. This experiment can be interpreted as a movement away from the identical information equilibrium if we begin with $\sigma_{f}^{2}=\sigma_{f}^{* 2}$, and then change only $\sigma_{f}^{2}$.

In this case, with $\sigma_{f}^{2} \neq \sigma_{f}^{* 2}, A$ and $A^{*}$ differ, as well as $C$ and $C^{*}$ and $Z$ and $2^{\star}$. So the equilibrium condition, from equation [29], is now

$[35] b=\frac{1}{R A}[D+C+R Z] w+\frac{1}{R A^{\star}}\left[D+C^{\star}+R Z^{\star}\right](1-w)$. 
Note here that since $A \neq A^{*}$ we cannot linearize the solution, as before, and that we could easily assume $R \neq R^{*}$ without further complicating the analysis. We consider a change in information to be more interesting that a change in the taste for risk.

If we isolate the terms in $D$ in equation [35], we obtain

$[36] b=D\left[\frac{w}{R A}+\frac{1-w}{R A^{\star}}\right]+\frac{C+R Z}{R A}+(1-w) \frac{C^{*}+R Z^{*}}{R A^{*}}$

The home perception of riskiness of return on the foreign asset $\sigma_{f}^{2}$ enters only in $A$ and $Z$, with $\partial A / \partial \sigma_{f}^{2}=\partial Z / \partial \sigma_{f}^{2}=1$. We can totally differentiate [36], allowing $D$ and $\sigma_{f}^{2}$ to change, use the solution for $\lambda$ in a substitution, and solve for $\mathrm{dD} / \mathrm{do}_{\mathrm{f}}^{2}$ to obtain the result:

[37] $\frac{\mathrm{dD}}{\mathrm{dd}_{\mathrm{f}}^{2}}=\frac{\frac{w}{\mathrm{~A}}(\lambda-1)}{\left(\frac{w}{R A}+\frac{1-w}{R A^{\star}}\right)}<0$.

The numerator is negative and denominator positive.

This result is intuitively clear. Given $\sigma_{f}^{* 2}$, an increase in $\sigma_{f}^{2}$ drives home investors toward the home asset, reducing D. The expression for $a \lambda / \partial \sigma_{f}$ in [19] shows the shift in demend for the home asset. But $\partial \lambda^{*} / \partial \sigma_{f}^{2}=0$, since $\sigma_{f}^{* 2}$, not $\sigma_{f}^{2}$, enters the foreign investors' demand functions. So only home investors shift home in this case, while in the case of identical information all investors shift toward the home asset.

A decrease in $\sigma_{f}^{2}$, representing an improvement in home investors' information about forelgn assets, would increase D, raising the home interest rate $i_{d}$ relative to the foreign rate $i_{f}$. Thus one implication of the European 
financial reforms of 1992 might be to reduce interest rates (and the cost of capital) in Europe relative to outside Europe.

Next we turn to the case where $\sigma_{f}$ changes, holding all $r$ 's constant. This is the equivalent of the second experiment earlier, but with only the home investor's demand functions shifting. Terms in $\sigma_{f}$ or $p_{f i}$ enter $A, C$, and $Z$ in equation [36]; their derivatives with respect to $\sigma_{f}$ are given in equation [33]. We totally differentiate equation [36], allowing $D$ and $\sigma_{f}$ to change, holding all r $\mathrm{fi}^{\prime}$ 's constant, use the solution for $\lambda$ in a substitution, substitute the expressions in [32] for $\partial A / \partial \sigma_{f}, \partial Z / \partial \sigma_{f}$, and $\partial C / \partial \sigma_{f}$ to obtain the following result:

[38] $\frac{\mathrm{dD}}{\mathrm{d \sigma}}{ }_{f}=-\frac{\mathrm{N}}{\left(\frac{\omega}{R A}+\frac{1-\omega}{R A^{\star}}\right)} \geqslant 0$ as $N \lessgtr 0$,

$$
\begin{aligned}
& \text { where }=\frac{W}{A}\left\{2(1-\lambda) \sigma_{f}+(2 \lambda-1) \sigma_{b} r_{b f}+\left[2(1-\lambda)-\frac{1}{R}\right] \sigma_{e} I_{e f}\right. \\
& \left.-\left(1-\frac{1}{R}\right) \sigma_{p} I_{p f}\right\}=w \frac{\partial \lambda}{\partial \sigma_{f}},
\end{aligned}
$$

and $\partial \lambda / \partial \sigma_{f}$ is given in equation [19] earlier. Note that, as in the case of identical information, if all $\mathrm{r}^{\prime} \mathrm{s}$ were zero, equation [38] would be equivalent to $[37]$.

Since only the home investors' demands shift in this case, the home demand shift is in the numerator of $\partial D / \partial \sigma_{f}$. The direct effect via $\sigma_{f}$ is to reduce $D$ as $\sigma_{f} r i s e s$, as before. The effect via the $\sigma_{e} r_{e f}$ term is uncertain, as discussed earlier. Since $R>1, \lambda<0.5$ is sufficient for this covariance effect to be positive. 


\section{Market Equilibrium with Symmetric Blased Information}

The last case we examine is one in which both sets of investors are assumed to have better information about their home assets than the foreign assets. This is a symmetric version of the case just discussed. We assume that it is possible that $\sigma_{f} \neq \sigma_{f}^{*}$ and $\sigma_{b} \neq \sigma_{b}^{*}$, where the starred versions are the foreign investors' estimates of the riskiness of returns. In this framework we can examine the effect of a symmetric change in perceived risk by changing $\sigma_{f}$ and $\sigma_{b}^{\star}$, holding $\sigma_{f}^{\star}$ and $\sigma_{b}$ constant. We will assume the changes in $\sigma_{f}$ and $\sigma_{b}^{*}$ are equal to a common $d o$. We will then solve for the effects on $D$ in equation [36] in the two cases in which (a) all relevant $p$ 's are held constant, and (b) all i's are held constant.

Since the total differentiation of [36] effectively linearizes it, we would expect the case of a change in symmetrically biased information to add a term in the forefgn demand shift to the numerators in the expressions in equations [37] and [38] in the case of one-sided bias, with the opposite sign. This is indeed the case.

First, we note that the terms in do will enter the differentiels of $A, C$, and $Z$ in equation [36], and the terms in $d \sigma_{b}^{*}$ will enter the differentials of $A^{\star}, C^{\star}$, and $Z^{\star}$. Totally differentiating [36], allowing $D, \sigma_{f}^{2}$, and $\sigma_{b}^{*}$ to change, holding all relevant $\rho$ 's constant, yields

[39] $\frac{\mathrm{dD}}{\mathrm{d \sigma ^{2 }}}=\frac{\frac{\omega}{\mathrm{A}}(\lambda-1)+\frac{1-\omega}{A^{\star}}\left(\lambda^{*}\right)}{\left(\frac{w}{R A}+\frac{1-w}{R A^{\star}}\right)}$.

Here the two demand shifts have offsetting effects on $D$. With a symmetric increase in perceived riskiness of the foreign return, both sets of investors shift toward the home asset. So the sign of the numerator in [39] depends on 
the net effect of the two shifts. If the entire model is symetric, with $A=$ $A^{*}, w=1-w$, and $(1-\lambda)=\lambda^{*}$, then $\mathrm{dD} / \mathrm{d} \sigma^{2}$ in [39] is zero.

Turning to the case where all relevant $r$ 's are held constant, we must

first write the partial derivatives of $A^{*}, C^{*}$, and $Z^{*}$ with respect to $\sigma_{b}^{*}$, noting that in their previous definitions $\sigma_{b}$ is replaced by $\sigma_{b}^{*}$ :

$$
\frac{\partial A^{*}}{\partial \sigma_{b}^{*}}=2 \sigma_{b}-2 \sigma_{f} r_{b f}^{*}-2 \sigma_{e} r_{e f}^{*} ;
$$

[40] $\frac{\partial C^{\star}}{\partial \sigma_{b}^{*}}=-\sigma_{e} r_{e b}^{*}-\sigma_{p^{*}} r_{b p^{*}}^{*} ;$

$$
\frac{\partial Z^{\star}}{\partial \sigma_{b}^{\star}}=-\sigma_{f} I_{b f}^{*}+\sigma_{p^{*}} I_{b p^{*}}^{*}
$$

Now to obtain the solution for $\partial D / \partial \sigma$, we totally differentiate [36] allowing A, $A^{*}, C, C^{\star}, Z, Z^{\star}$, and $D$ to change, and then substitute from [33] for $\partial A^{*} / \partial \sigma \sigma_{b}$, etc. to obtain

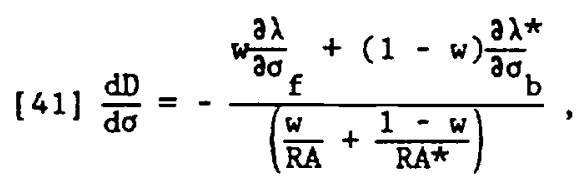

where $\partial \lambda / \partial \sigma_{f}$ is given by equation [19], likely to be positive, and $\partial \lambda * / \partial \sigma_{b}$ is given by equation $[26], 1$ ikely to be negative.

Although it is not obvious from the form in which [41] is written, if all I's are assumed to be zero, it is equivalent to [39]. Again, the two demand shifts have offsetting effects. It is obvious in [41] that if $w=1-w$ and the two demand partials were equal in size, the effect on $D$ would be zero. But this is not likely to be the case, because the terms in the two partials are 
not the same. But the general result from the cases of biased information is that a one-sided improvement moves the investors with the improvement toward that asset, reducing its relative expected return, while the effects are offsetting with a two-sided improvement.

\section{CONCLUSIONS: THE EFFECTS OF IMPROVING INFORMATION}

We can now summarize our main conclusions concerning the influence of information on portfolio decisions. A change in information always has the direct effect, of course, of causing investors in each of the countries to alter their portfolio decisions. But this is only the starting point for analyzing the effects of changing information. For one thing, by aggregating investor demand across countries, the effects of changing information on home asset preference and on security risk premiums can also be deduced. For another thing, if access to information varies by country, then changes in information will have differential effects on investors in different countries.

We assume in all cases that there are two countries--a home country and a foreign country--each with a single risky investment asset. There then ensues an improvement in information regarding investments in the foreign asset (the asset in the foreign country). We will focus in this section on the case in which the improvement in information reduces the variance of the return on the foreign asset, while all covariances involving the foreign asset remain fixed. 14

14 If the foreign asset variance changes while its covariances are constant, then all the correlation coefficients involving the foreign asset must be changing. 
In Section 3, we derfued comparable results for special cases, given that the variance and covariance terms vary in proportion. 15

We now summarfze the results of a series of cases in which investors have varying amounts of access to information changes.

\section{Identical Access to Information}

We first consfder the case in which all investors have identical access to information, so that the reduced risk of the foreign asset is equally apparent to all of them. The direct result is that investors in both countries allocate a larger share of thefr portfolios to the foreign asset, as can be seen in equations [18] and [24]. Since the fmproved information raises the demand for the foreign asset, it w1ll also reduce the foreign asset risk premium--the sum of the nominal return on the foreign asset and the expected depreciation of the home currency minus the nominal return on the home asset--as shown in equation $[31]$.

The size of the fncrease in demand for each group of investors is proportional, moreover, to the portfollo share initially allocated to the foreign asset. 16 Consequently, if home asset preference is zero initially-portfolio shares are the same for home and foreign investors--then the change in information does not affect home asset preference. Alternatively, if home

15 In this case, the correlation coefficients must be constant. Constant correlation coefficients and constant covariance terms yield the same resul= if the correlation coefficients are all zero, or if the correlation coefficients meet the other sufficient conditions identified in section 3.

16 For example, from equation [18], it is easy to see that $\frac{d(1-\lambda)}{d \sigma_{f}^{2}}=-(1 / A)(1-\lambda)$. 
asset preference is positive--the foreign asset share is higher for foreign investors than for home investors--then home asset preference will rise as foreign asset information improves.

\section{Asymmetric Access to Information}

As a second case, it is assumed that the home and foreign investors have differential access to information regarding the foreign asset. In particular, in Section 3, we examined the case in which home country investors, and only home country investors, observe an improvement in foreign asset information. This could correspond, for example, to a case in which better information regarding European securities becomes available to non-European investors.

The direct result is again that the relevant investors--only the home country investors in this case--increase the share of their portfolios allocated to the foreign asset. The demand by foreign investors does not change since, by assumption, there is no change in the information available to them. Given that foreign asset demand rises overall, the foreign asset risk premium will fall, just as it did in the case of identical information (see equation [37]). Of course, the magnitude of the change in the risk premiur will be limited, because the change in information is assumed to affect only one group of investors.

Since only the foreign asset demand of home country investors rises, the information change also has the effect of reducing the magnitude of home asset preference. For example, if home asset preference were initially positive, then it would fall as home country investors allocate a larger share of their portfolios to the foreign asset. 


\section{Symmetric But Biased Access to Information}

As the third case, it is assumed that both home and foreign investors receive improved information, but regarding only the assets of their own country: the home asset for home investors, and the foreign asset for foreign investors. The result is that home investor demand shifts toward the home asset, while foreign investor demand shifts toward the foreign asset. Home asset preference thus unambiguously increases. Moreover, the two shifts in demand occur in opposite directions, so if they are also equal in magnitude, then there will be no net effect on equilibrium risk premiums. This is a good illustration of the complex manner in which information can interact with real interest rate spreads.

\section{Applicetions to "Europe 1992"}

In using these results to analyze "Europe 1992," the most relevant case would appear to be an asymmetric change in information, in which home country investors (non-Europeans) observe a decline in the riskiness of foreign (European) assets. As we have just seen, the result should be an increase in demand and a reduction in the risk premiums with regerd to European securities. The beneficiaries of this change would include both non-European investors and European borrowers (issuers of securities).

The overall results of "Europe 1992," however, may be more complex than this simple, direct, effect suggests. For example, non-European investors may be surprised to find that improved information results in lower, not higher, expected returns on European securities. In other words, the benefits of reduced uncertainty may seem subtle compared to the reduction in expected 
returns caused by the demand shift. The complex nature of evaluating welfare effects when information changes is also illustrated in the paper by Bruce Miller and Thomas Copeland, "The Welfare Effects of Public Information in an Asymmetric Information Market," which also appears in this symposium.

More generally, the information changes created by "Europe 1992" may be the source of a variety of additional effects, some of which we can now examine. An immediate point is that a change in risk premium levels creates losers as well as gainers. For example, as the risk premiums on European securities fall, European investors will earn lower returns on their local investments. European investors will thus lose some or all of the excess return they had been earning as a result of their informational advantage. Accounting for gainers and losers will become even more complex to the extent that European investors will also gain from improved intra-European information. For example, French investors may obtain better information with regard to Spanish investments. Consequently, a French investor will benefit from improved information regarding his non-French European investments, even while he is losing with regard to French investments.

Another factor is that the improvements in information may be restricted to certain classes of European securities. For example, additional information may become available primarily for publicly traded debt and equity securities, where unform accounting and reporting standards are relevant. In contrast, changes of this form are unlikely to create benefits for bank loans that are originated in local markets and held by local banks. 17 Nevertheless, interest rates on bank loans may still decline, assuming that "Europe 1992" encourages

17 See Jaffee and Stiglitz [1989], for a discussion of the informational aspects of bank lending. 
entry by foreign banks into local markets as part of banking industry deregulation.

The changes created by "Europe 1992" may even increase the riskiness of certain European securities. A particularly intriguing possibility is that the government bonds of European countries may become risky as these countries lose their autonomy with regard to monetary and fiscal policy. In this case, the government bonds of European countries would be similar to the bonds issued by varlous state governments within the United States. The result, of course, would be an increase in the interest rates for these securities.

The Role of Information for Real Interest Spreads

This paper began by noting that real interest rate levels in countries could vary as the result of risk premiums. Although the finance literature has focused on such factors as unequal distributions for wealth and securities, or different consumption preferences, as the source of real interest rate spreads, we have shown that imperfect information may be an equally important source of these rate spreads.

In particular, an improvement in information will generally be reflected in reduced real interest rate spreads. Although such changes are usually beneficial, there will be a distribution of gainers and losers. With regard to "Europe 1992," for example, the reduction in real interest rate spreads will also reflect, among other things, a reduction in the ability of European central banks to control their domestic interest rates through monetary policy. 


\section{RKFERENCES}

Adler, Micheel, and Bernard Dumas [1983], "International Portfolio Choice and Corporation Finance: A Synthesis," Journal of Finance, 38, 925-984.

Adler, Michael, and Bruce Lehmann [1983], "Deviations from Purchasing Power Parity in the Long Run, Journal of Finance, 38, 1471-1487.

Barry, Christopher B. and Stephen J. Brown [1985], "Differential Information and Security Market Equilibrium," Journal of Financial and Quantitative Analysis, 20, 407-422.

Bawa, Vijay S., Stephen J. Brown, and Roger W. Klein [1979], Estimation Risk and Optimal Portfolio Cholce, North-Holland Publishing Compeny.

Black, Fischer [1974], "International Capital Market Equilibrium with Investment Barriers," Journal of Financial Economics 1, 337-352.

Branson, William h. and Dale Henderson, [1985], "The Specification and Influence of Asset Markets," in R.W. Jones and P.B. Kenen editors, Handbook of International Economics, vol. II. Elsevier Science Publishers.

Brown, S. [1979], "The Effect of Estimetion Risk on Capital Market Equilibrium," Journal of Financial and Quantitative Analysis, 14, 215-220.

Fraga, Arminio [1986], "Price Uncertainty and the Exchange-Rate Risk Premium," Journal of International Economics, 20, 179-185.

Frankel, Jeffrey A. [1989], "Quantifylng International Capital Mobility in the 1980s," NBER Working Paper No. 2856.

Frankel, Jeffrey A. and Alan T. MacArthur [1988], "Political vs. Currency Premia in International Real Interest Differentials," European Economic Review, $32,1083-1121$.

Frenkel, Jacob A. [1981], "Flexible Exchange Rates, Prices and the Role of "News': Lessons from the 1970s," Journal of Political Economy, 89, 665-705.

Grossman, Sanford J. and Joseph E. Stiglitz [1980], "On the Impossibility of Informationally Efficient Markets," American Economic Review, 70, 393-408.

Ho, Thomas S. Y. and Roni Michaely [1988], "Information Quality and Market Efficiency," Journal of Financial and Quantitative Analysis, 23, 53-70.

Jaffee, Dwight M. and Joseph Stiglitz [1989], "Credit Rationing," forthcoming In Berjamin Friedman editor, Handbook in Financial Economics.

Merton, Robert C. [1987], "A Simple Model of Capital Market Equilibrium with Incomplete Information," Journal of Finance, 42, 483-510. 
Obstfeld, Maurice [1986], "Capital Mobility in the World Economy: Theory and Measurement," Carnegis-Rochester Series on Public Policy 24, Spring, pp. 55103.

Stein, Jeremy C., [1987], "Informational Externalities and Welfare-Reducing Speculation," 95, 1123-1145.

Stulz, Rene M. [1981], "On the Effects of Barriers to International Investment," Journal of Finance, 36, 923-934. 


\section{Purchan log Pourer Parits}

Purchasing power parity requires that the exchange rate qual the rat lo of the price levels of the two countries:

$\mid a .11 \quad E=\frac{P}{p^{-}}$

The dynamic process for the exchange rate is then:

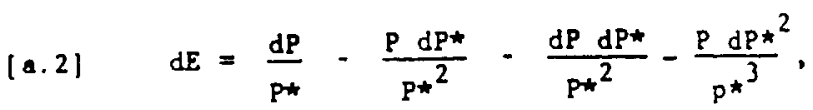

which can be rowritten using [a.1) as:

[a.3) $\frac{d E}{E}=\frac{d P}{\bar{P}}-\frac{d P^{\star}}{P^{\star}}-\frac{d P d p^{\star}}{P P^{\star}}-\left(\frac{d P^{\star}}{P^{\star}}\right)^{2}$,

Making subatitutions based on equations [11] to [13] yields:

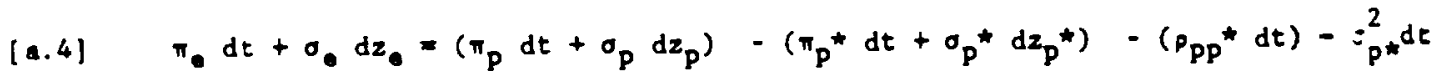

Ex ante purchasing power partty holds when the expected changes in [a.4], that is the terms in $d t$, are equal:

$[0.5] \quad \pi_{0}=\pi_{p}-\pi_{p} *-p_{p P} *-z_{p^{*}}^{2}$

Ex post purchasing power parity holds whon, in addition, the stochastic terms In $[\mathbf{4 . 4}]$ are equal:

$$
\sigma_{\bullet} d z_{\bullet}=\sigma_{p} d z_{p}-\sigma_{p} * d z_{p} *
$$


Hultiplying through by $\sigma_{e} d z_{e}$, we then have:

$[a .6] \quad \sigma_{e}^{2}=p_{e p}-p_{e p}{ }^{*}$

where $P$ ep and $P_{e p}$ are the covarlances of $P$ and $P^{*}$ respectively with respect

to the exchenge rate.

\section{Uncovered Interest Rate Parity}

Uncovered Interest rate parity (UIP) as seen by the home. Investor requires that:

[a.7] $\quad \frac{\mathrm{dB}}{\mathrm{B}}=\frac{\mathrm{d}(\mathrm{EF})}{\mathrm{EF}}$

Making substitutions based on equations [9] to [11], we have:

[a.8] $1_{b} d t+\sigma_{b} d z_{b}=1_{f} d t+\sigma_{f} d z_{f}+\left(\pi_{e}+o_{e f}\right) d t+\sigma_{e} d z_{e}$

Ex ante UIP requires that the expected terms in equation [a.8] be equal:

[a.9] $\quad 1_{b}-1_{f}-\pi_{e}-\rho_{e f}=0$

Ex post UIP requires, in addition, that the stochastic terms in [a.8] be equal:

$$
\sigma_{b} d z_{b}=\sigma_{f} d z_{f}+\sigma_{e} d z_{e}
$$

Multiplying through by $\sigma_{e} d z_{e}$ we then have:

[a.10] $\sigma_{e}^{2}-p_{e b}+p_{e f}=0$. 